\title{
Immediate implant placement with guided bone regeneration using a non-resorbable membrane - Case report
}

\author{
Amante $L^{1}$, Mamede $D^{1}$ \\ Affiliations: \\ 1. United Kingdom \\ Corresponding author \\ Luis Filipe Amante \\ luis.filipe.amante@gmail.com
}

\section{ABSTRACT}

Purpose: The usage of non-resorbable membranes in guided bone regeneration (GBR) has been widely described in the literature as a valid treatment option to address horizontal and vertical alveolar bone defects in implant dentistry. It's also consensual that factors such as the stability of the membrane, the surgical technique, the gingival biotype, the blood supply and the postoperative care, play an essential role on the success and predictability of the augmentation. The purpose of this article is to describe a clinical case where a non-resorbable membrane was used following the immediate placement of two dental implants in the maxilla.

Case report: This case report describes a clinical case where the upper right lateral incisor and the upper right canine where extracted followed by the immediate placement of two dental implants. A Titanium membrane was used on the socket of the lateral incisor to stabilize a xenograft placed in the buccal alveolar defect. The membrane used was directly connected to the implant connection which facilitated its surgical placement stability and removal. After 4 months, upon removing the membrane, it was evident that there was a satisfactory horizontal bone regeneration. The impressions stage followed and two screw-retained porcelain bonded crowns were finally fitted.

Conclusion: The authors have found that the usage of a non-resorbable membrane allowed a predictable horizontal bone augmentation in this clinical case. The results obtained were quite rewarding for both clinicians and patient and remain functional and stable as confirmed with the two-year clinical follow up and CBCT scan results.

\section{KEYWORDS}

Guided bone regeneration, ridge augmentation, dental implant therapy, nonresorbable membranes 


\section{INTRODUCTION}

The long-term success of dental implants is highly dependent upon the degree of osseointegration in sufficient and healthy bone. ${ }^{1,2}$ In the daily practice of an implant surgeon alveolar ridge defects are quite commonly seen and to overlook them when planning and performing implant therapy is a recipe for disaster. Alveolar ridge resorption following tooth extraction is a common phenomenon, this is a progressive and irreversible condition that results on a reduction of the alveolar ridge's height and width particularly in the first year. The loss of teeth determines the loss of the functional stimulus of the alveolar bone. Consequently, the bone undergoes constant and predictable resorption, which differs depending on location. The degree of resorption is greater at the buccal aspect than at the lingual/palatal aspect and the alveolar bone reduction is greater in the molar region., 3,45

The biological principle of guided bone regeneration (GBR) has been widely used to address alveolar defects and its advantages to the patient include: a reduced volume loss of the alveolar ridge, accelerated tissue regeneration, a reduced need for additional grafting and increased possibility of future/ immediate implant installation and stability and preservation of aesthetic on osseointegrated implants. It's estimated that about $40 \%$ of dental implant placements world-wide have some form of bone regeneration procedure done simultaneously. ${ }^{6} \mathrm{GBR}$ is often recommended for an implant site with buccal dehiscence or fenestration defects ${ }^{7}$, Grunder et al. also stated that implant sites with thin buccal bone plates in the aesthetic area could be indicated for GBR procedures in order to prevent future gingival recession. ${ }^{8}$ Different investigators have examined the efficacy of the GBR technique for treatment of osseous defects of varying sizes surrounding dental implants. Such studies have reported different degrees of success of GBR, depending upon the type of barrier used, the presence or absence of grafting material, the feasibility of technique, and clinician's preference, among other factors. ${ }^{9-13}$ As the concept of bone regeneration has continued to develop, multiple techniques have become available, with a variety of materials to stimulate new bone growth around implants. To achieve desirable outcomes and maximal effectiveness, the selection of osseous grafting materials should be based on their unique features, therapeutic objectives, and indications. ${ }^{14}$ The materials used for bone augmentation are divided into natural (autografts, allografts and xenografts) and synthetic materials. These graft materials are used for clinical applications based on the hypothesis that they are osteogenic, osteoinductive, osteoconductive or possess a combination of these proprieties. ${ }^{15}$ Several techniques and different graft materials have been used with satisfactory results in $\mathrm{GBR}^{16}$ and Fiorellini et al demonstrated that implant osseointegration can be successfully achieved with non-resorbable membranes regardless of the type of osseous grafts used. ${ }^{17}$ The role of barrier membranes in GBR is crucial for proper bone regeneration. It can prevent in-growth of soft tissue in the bone defect and maintain the defect space during bone tissue regeneration. The desirable characteristics of the membrane used for GBR therapy include biocompatibility, cell-occlusion properties, integration by the host tissues, clinical manageability, space-making ability and adequate mechanical and physical properties. Non-resorbable membranes, mainly polytetrafluoroethylene (PTFE) constituted the first generation of barrier membranes but in recent years resorbable membranes have become more popular and widely used. Clinical studies demonstrate that GBR is predictable and successful for horizontal defect augmentation and in most situation, this can be achieved using either non-resorbable or resorbable membranes. ${ }^{18}$ Resorbable membranes have the advantage of being user friendly particularly because they avoid the need for a re-entry approach to remove them. Furthermore, although superior outcome has been revealed using nonresorbable membranes, several reports indicate that such membranes are susceptible to higher complication rates. ${ }^{19,20}$ This has mostly been associated with exposure through the soft tissue, in combination with lack of vascular supply. The main reasons for GBR failure are poor bone augmentation as a result of soft tissue invasion and graft shrinkage due to poor blood supply. Granulation tissue formation and lack of adequate callus formation are generally caused by graft instability, exposure of grafting material and infection. . $1,22^{2}$

A resorbable membrane will provide a barrier and will secure the graft, nevertheless there is some associated unpredictably that is out of the clinician's control. On the other hand, a nonresorbable membrane is within the clinician's control, but may perforate the tissues and produce unwanted complications. ${ }^{23}$ Each membrane type thus similarly has its own biological and mechanical properties, its own pros and cons. ${ }^{24}$ Possibly the first report of titanium membranes used in GBR was published by Celleti et al, 1994. ${ }^{25}$ Thus the introduction of these materials into the literature are not altogether new, but their wider commercial availability and use now may be. A titanium sheeting device when adapted to the alveolar ridge provides a semi-permanently rigid scaffold surrounding the graft material and can be fixed to the dental implant itself. In the recent years the I-Gen membrane was introduced. This is a titanium mesh, that has been designed for horizontal and vertical ridge augmentation and it is to be fixed on the implant. I-Gen is a flexible membrane which is easy to place, fix and create 3D bone shape and can be removed easily but there is still a lack of clinical studies evaluating the efficiency and predictability of these membranes, particularly long term. ${ }^{26,27}$

There is a plethora of techniques with various combinations of grafting materials and different barriers that can be used in GBR in implant therapy. The decision of which GBR technique and what materials should be used for each specific case should be a result of the combination of the clinician's experience and the assessment of the clinical circumstances of the clinical case. The purpose of this article is to describe a clinical case where the authors decided to use a non-resorbable membrane for GBR following the immediate placement of two dental implants in the maxilla. 


\section{CASE REPORT}

The patient, JF, male 70 years attended the implant clinic for a consultation after having been referred by his general dental practitioner following a fractured right maxillary canine. This tooth had a history of root canal treatment and had recently been deemed unrestorable after having fractured at gum level. The clinical examination revealed that unfortunately the upper right lateral incisor was also of hopeless prognosis as it presented with a radicular fracture associated with a post crown, and its extraction was also advised. The patient was medically fit and healthy and had an ongoing prescription of simvastatin, he didn't smoke and consumed alcohol sporadically. He presented with a heavily restored dentition but a satisfactory oral hygiene and further to the above mentioned problems he was otherwise free from other carious or periodontal pathology. He had also been a regular attender to the dental practice where he had been a patient for some years attending usually twice a year for checkups and for yearly hygiene visits.

The protocol for implant treatment planning in our practice includes routinely a sequence of periapical $x$-rays, upper and lower study models with diagnostic wax-up, surgical stent, as well as intra and extra-oral photos (Figure 1, 2). A CBCT scan was recommended but unfortunately the patient declined as he didn't want to travel to get it done despite being having been told the importance of this exam from a diagnostic point of view. A detailed and thorough consent form was then produced and forwarded to the patient that was subsequently invited for an additional consultation to discuss it in detail. It was decided to proceed with the extraction of both of the inviable teeth and, if clinically feasible, to place two dental implants immediately in the two extraction sockets. It was stressed that, depending on the difficulty of the extractions and of the quality and quantity of bone at the time of the removal of the teeth, that a delayed placement may be advised and that possibly a procedure of guided bone regeneration could be indicated as well. This was clearly stated in the consent form and the patient was verbally instructed about this to great detail to ensure an adequate process of consent.

In the day of surgery, the patient attended for the procedure having taken three grams of amoxicillin one hour preoperatively for prophylactic purposes (there was no report of allergies to any medication). The procedure was done under local anaesthetic (Articaine hydrochloride 4\% with adrenaline 1:100,000, Septanest, Septodont) after three cartridges being infiltrated buccal-palatally. A sulcular incision was completed around the condemned teeth and the two adjacent teeth, together with two papilla sparing incisions. A full thickness flap was subsequently raised to allow a good operatory access and a satisfactory visualization of the surgical field (Figure 3). The extraction of the teeth followed (Figure 4) and it was clear that

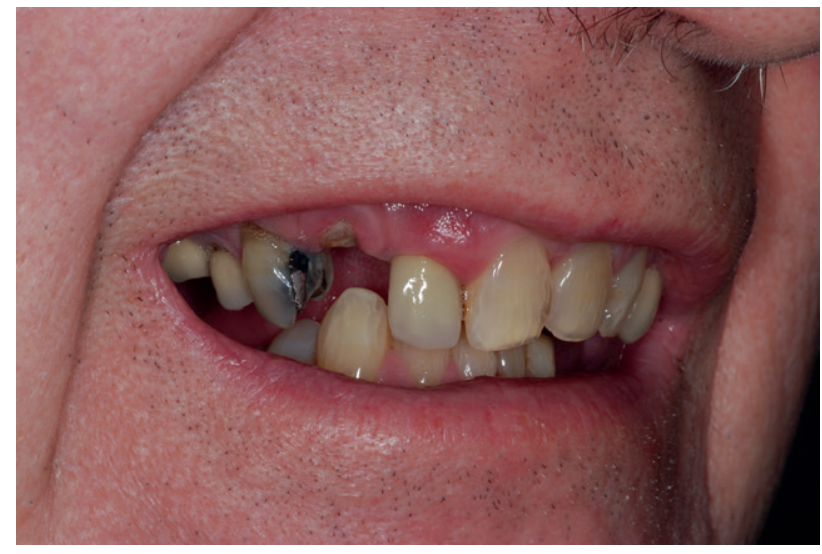

Figure 2. Pre-operative -extra oral photograph

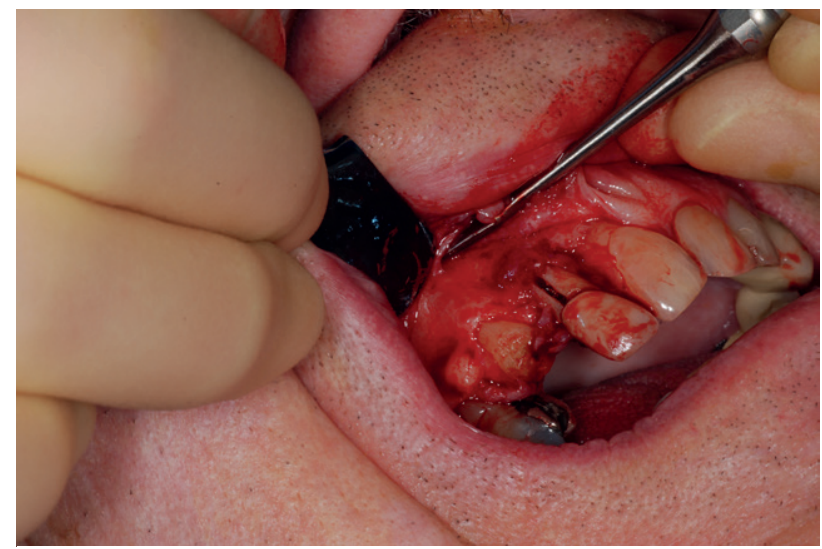

Figure 3. Peri-operative - full thickness flap raised

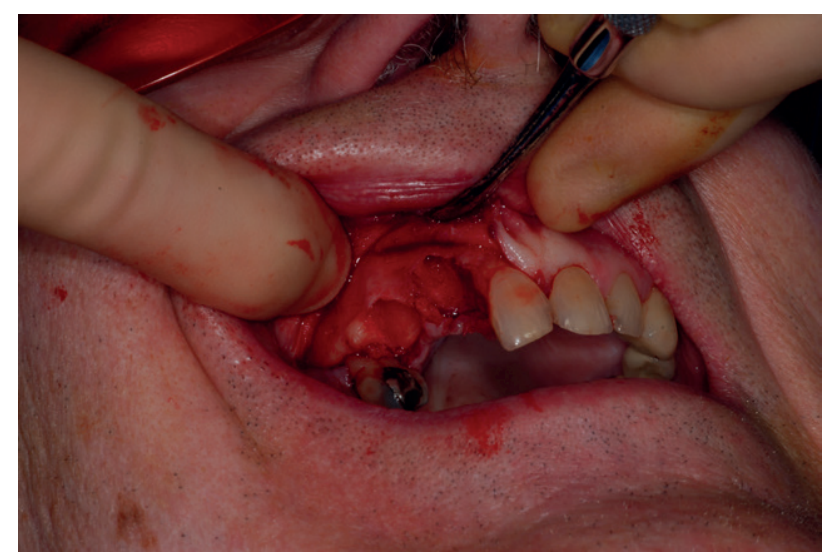

Figure 4. Peri-operative - post extraction

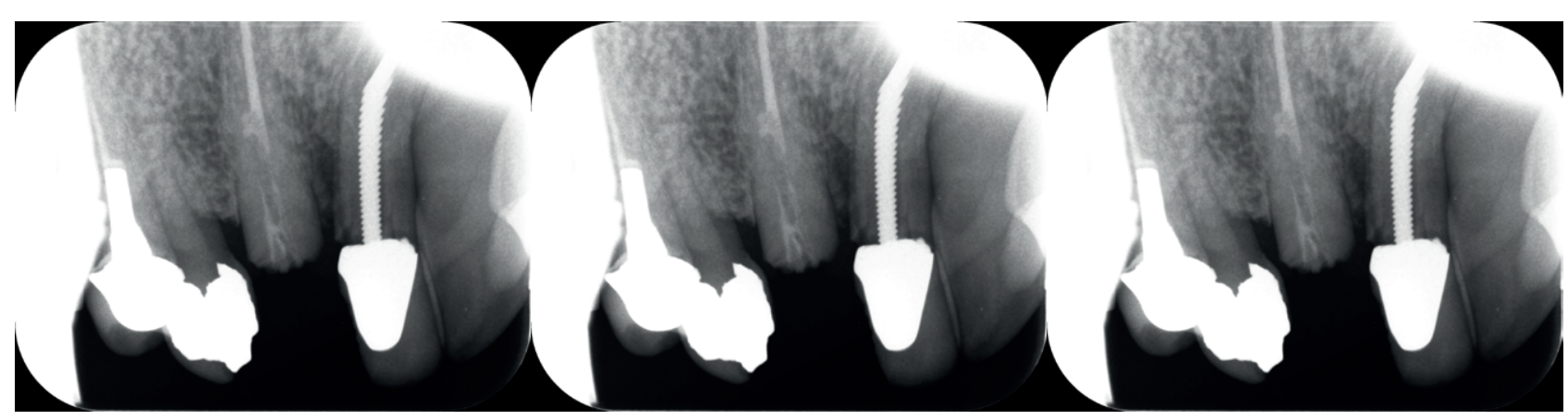

Figure 1. Pre-operative - periapical $x$-ray 
the upper right lateral incisor extraction socket presented with a noticeable buccal alveolar defect. A thorough curettage and alveolar irrigation was then performed using abundant amounts of saline. At this stage, after having assessed the bony walls of the sockets and the severity of the alveolar defect, it was decided to place two 4,5 x 11,5 implants (MegaGen Anyridge) immediately (Figure 5) and to use a non-resorbable titanium membrane to stabilize a xenograft (Geistlich Bio-oss ${ }^{\circ}$ Spongious bone substitute granules 0.25 to $1 \mathrm{~mm}, 0,5 \mathrm{~g}$ ) to allow the GBR of the buccal alveolar defect on the lateral incisor socket (Figure 6). The use of non-resorbable, titanium membranes can achieve GBR by ensuring graft stability and space maintenance so as to ensure optimal neovascularization, and the authors believed for this particular case this would be better indicated than a resorbable membrane. The membrane used (MegaGen i-Gen ${ }^{T M}$ ) allowed the clinicians to stabilize the graft without the need to use fixating pins as it is directly attached to the implant connection interface. There are different sizes available in order to be able to address the different alveolar defects, and in this case a C 1 iGen membrane was used as it was an adequate fit for this particular defect. After confirming the membrane's stability and checking if the flap design allowed an adequate tension-free coverage of the grafted area the area was then covered with an absorbable collagen membrane (Geistlich Bio-gide ") (Figure 7) and the surgical area was sutured thoroughly with non-absorbable 4.0s black silk sutures (Figure 8). The patient followed a thorough postoperative regime taking anti-inflammatory drugs every $8 \mathrm{~h}$ for $72 \mathrm{~h}$ (paracetamol 500mg and $400 \mathrm{mg}$ of ibuprofen) and rinsing with chlorhexidine mouthwash after his meals as well as brushing with a soft toothbrush. The gingival biotype had favourable thickness and the incision design allowed adequate vascularization of the grafted area. The removal of the sutures took place 10 days later revealing a promising healing process. After this period the patient waited for 4 months during which time he was using a removable acrylic denture with no buccal flange and alleviated to avoid unwanted pressure on the grafted area. Following this, the patient was then reviewed and both the clinical examination and the peri-apical x-ray showed promising results in regards to the outcome of the osseointegration as well as the success of the GBR (Figure 9). The membrane was then

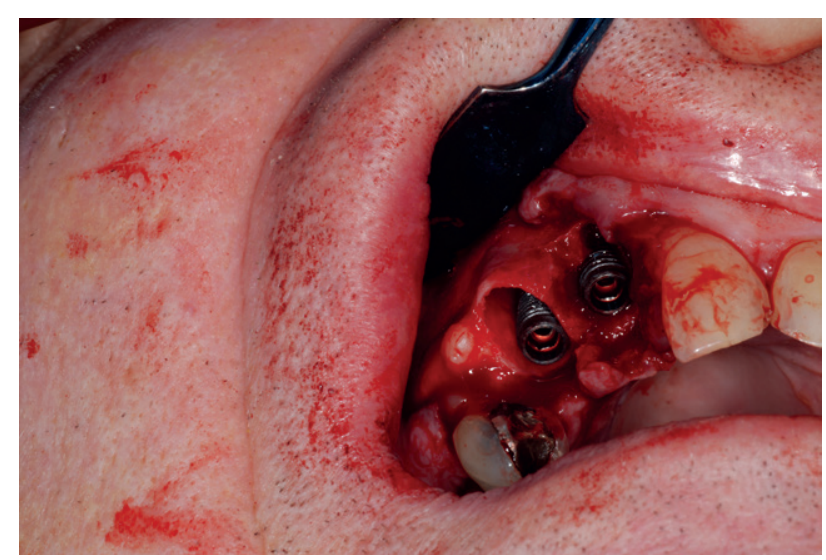

Figure 5. Peri-operative - implant placement

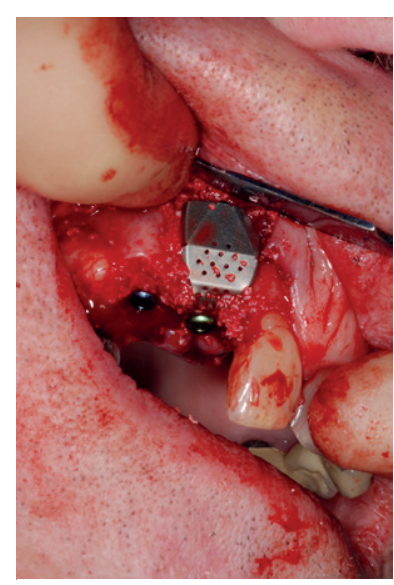

Figure 6. Peri-operative - nonresorbable membrane in situ

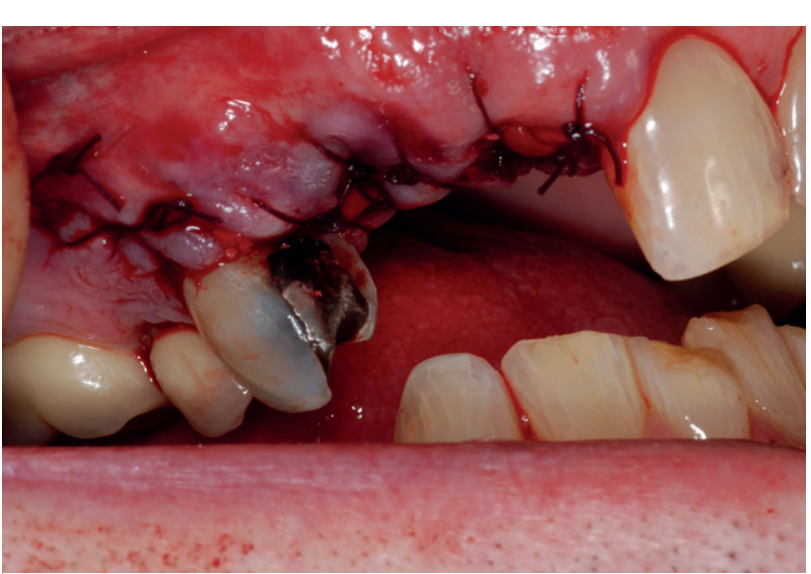

Figure 8. Post-operative - sutures

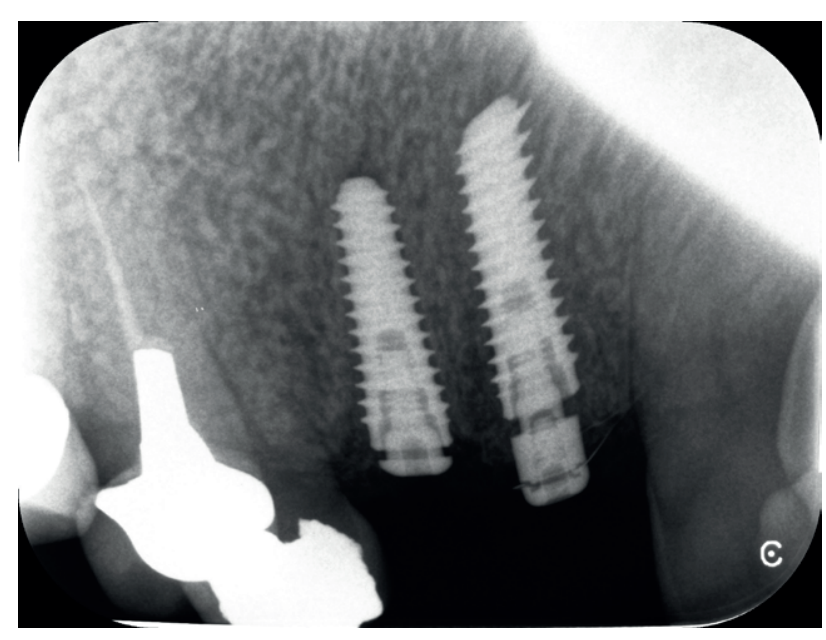

Figure 9. Post-operative $x$-ray

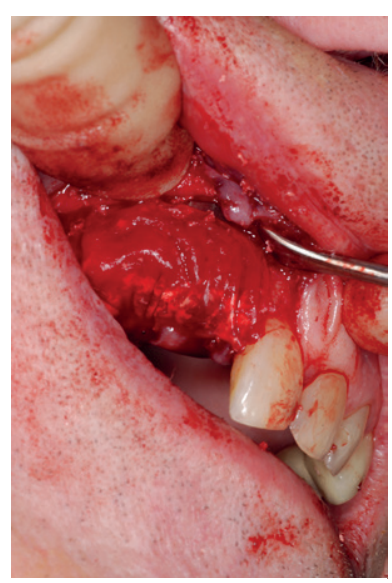

Figure 7. Peri-operative - absorbable membrane in situ 
removed easily with a very small incision done for this purpose (Figure 10) and the rehabilitation stage followed (Figure 11). Two porcelain bonded screw retained crowns were then provided by the lab technicians after a sequence of impressions, try-in and fit appointments (Figure 12, 13). The patient was extremely happy with the results and clinically the alveolar buccal bone and periimplant area seemed stable promising to help maintaining the two implants healthy, easy to clean and stable for years to come. The patient was followed up regularly subsequently and carried on with his regular visits to the GDP and the hygienist. In the twoyear implant follow-up appointment, it was decided to take a CBCT scan to ascertain the apparent stability of the implants and particularly of the buccal alveolar bone on the upper right lateral incisor. The results revealed that a good thickness of cortical and cancellous bone were present labially to the implant which pleased the clinical team immensely (Figure 14,15).

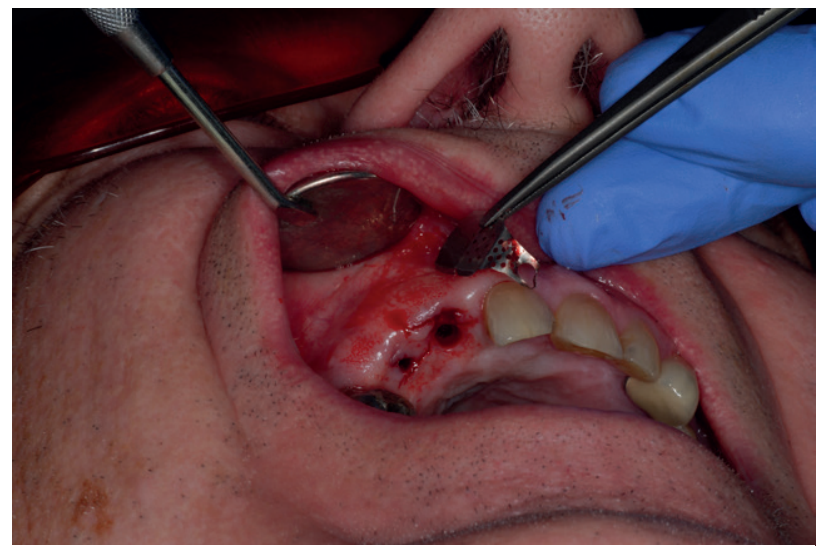

Figure 10. Non-resorbable membrane removal

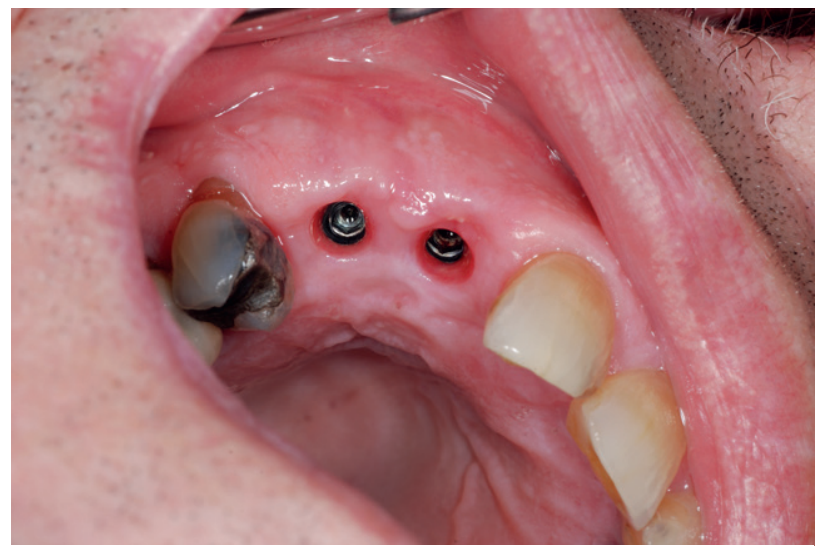

Figure 11. Impression stage

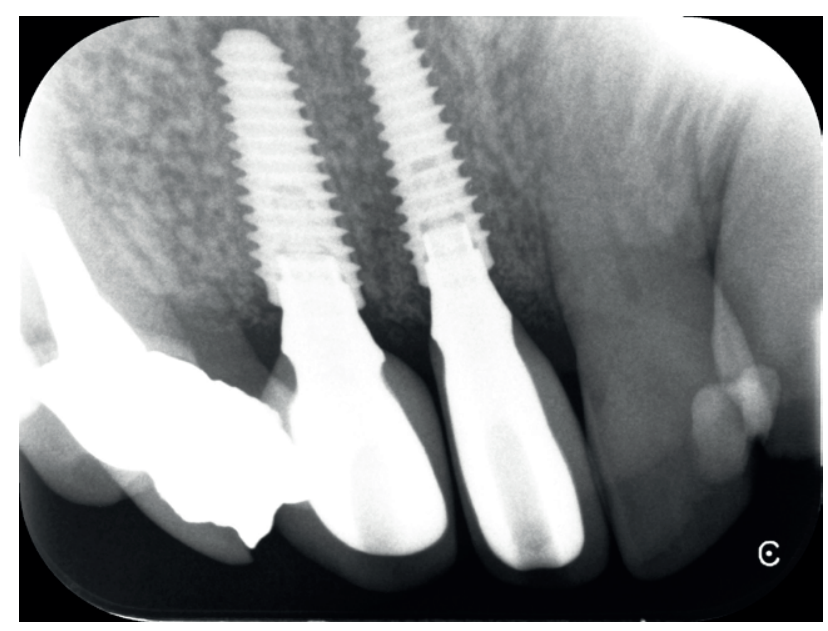

Figure 12. Fitting appointment - periapical x-ray

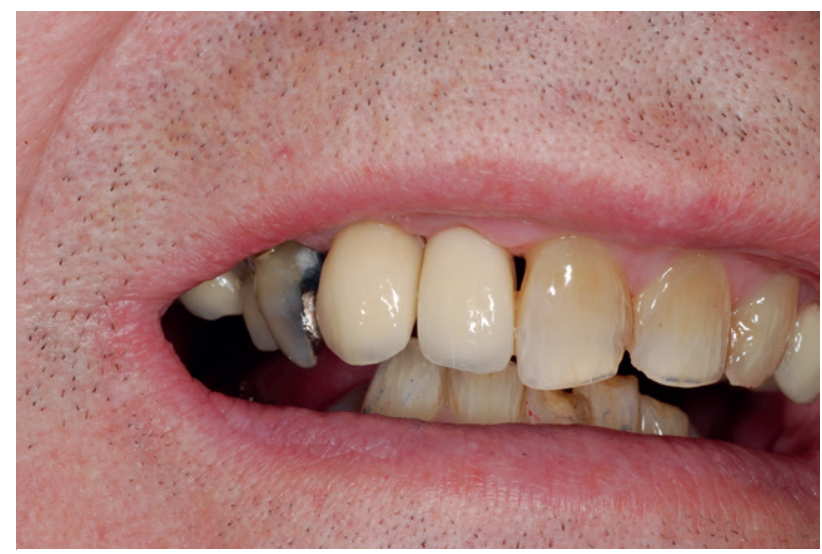

Figure 13. Fitting appointment - extra oral photograph

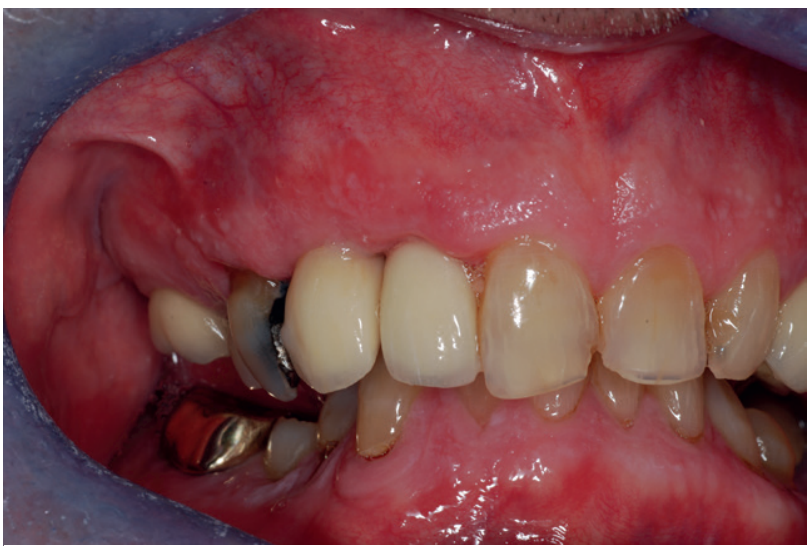

Figure 14. 2 year follow-up - intra oral photograph 

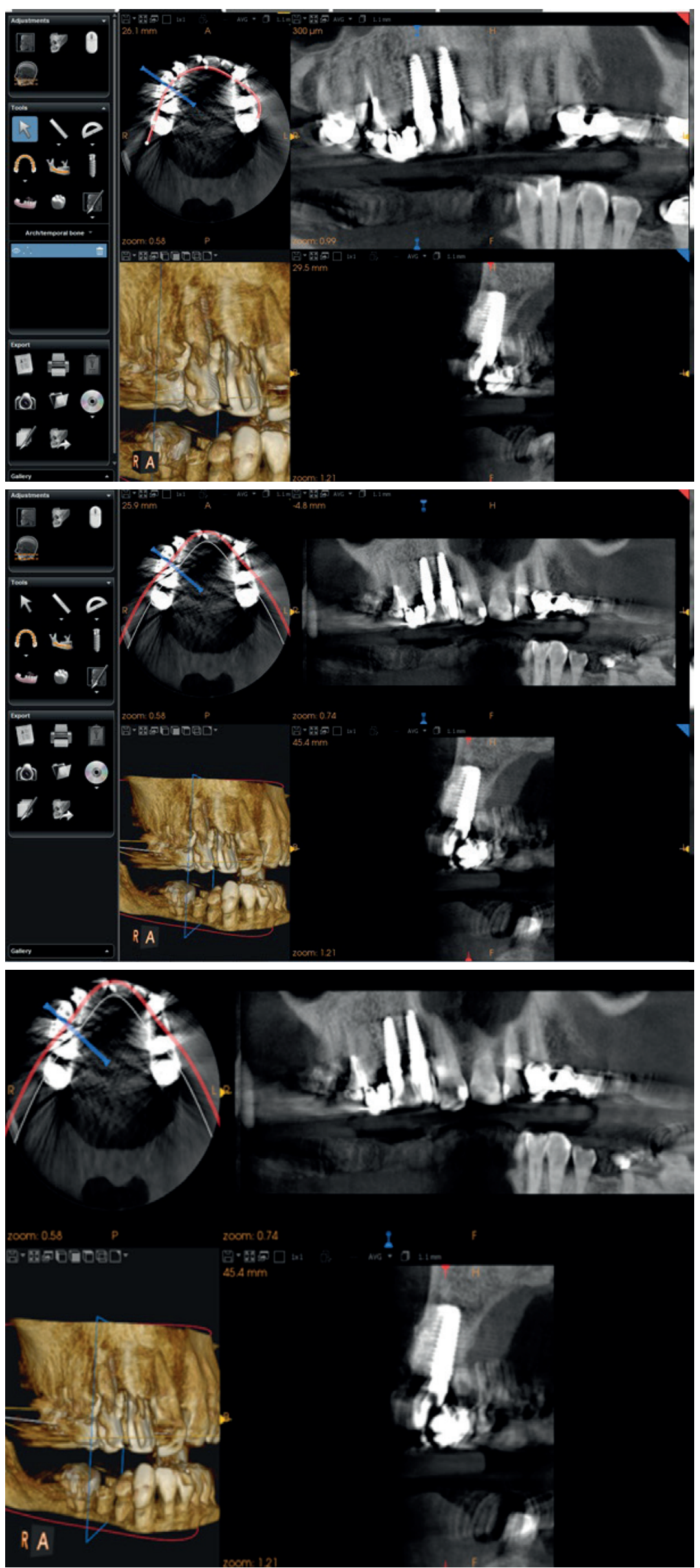

Figure 15. 2 year follow-up - CBCT scan 2 


\section{CONCLUSION}

The complex and challenging art of placing dental implants has a vast number of factors that need to be considered to achieve long term success. The modern and resourceful implant surgeon of today needs to master a number of techniques that will allow him to place implants in sufficient and healthy bone in a predictable fashion, and GBR should be definitely considered as a valid treatment option for this purpose. In this particular case the authors found that using a non-resorbable membrane with a xenograft and the immediate placement of the implants was an advisable treatment option according to their experience. The two-year clinical follow-up and CBCT scan results are promising and both clinicians and patient are quite happy with the results achieved so far.

\section{CONFLICT OF INTEREST}

The authors declares that there is no conflict of interest regarding the publication of this article.

\section{REFERENCES}

1. Rocchietta I, Fontana F, Simion M. Clinical outcomes of vertical bone augmentation to enable dental implant placement: a systematic review. J. Clinic. Periodontol. 2008 Aug; 35: 203-215.

2. Goto T. Osseointegration and dental implants. Clin. Calcium. 2014; 24: 265-271.

3. Hansson S, Halldin A. Alveolar ridge resorption after tooth extraction: A consequence of a fundamental principle of bone physiology. J. Dent. Biomech. 2012.

4. Schropp L, Wenzel A, Kostopoulos L, et al. Bone healing and soft tissue contour changes following single-tooth extraction: a clinical and radiographic 12 -month prospective study. Int J Periodontics Restorative Dent 2003; 23: 313-323.

5. Cucchi A, Vignudelli E, Napolitano A, Marchetti C, Corinaldesi. Evaluation of complication rates and vertical bone gain after guided bone regeneration with non-resorbable membranes versus titanium meshes and resorbable membranes. A randomized clinical trial. Clin Implant Dent Relat Res. 2017;19: 821-832.

6. Bornstein M, Halbritter S, Harnisch H, Weber H, Buser D. A retrospective analysis of patients referred for implant placement to a specialty clinic: indications, surgical procedures, and early failures. J Oral Maxillofac Implants 2008 Nov-Dec; 23(6): 1109-16.

7. Buser D, Halbritter S, Hart C, Bornstein M, Grutter L. Early Implant Placement With Simultaneous Guided Bone Regeneration Following Single-Tooth Extraction in the Esthetic Zone: 12-Month Results of a Prospective Study With 20 Consecutive Patients. Journal of Periodontology.

8. Grunder U, Gracis S, Capelli M. Influence of the 3-d bone-to-implant relationship on esthetics. International Journal of Periodontics and Restorative Dentistry 2005; 25: 113-19.

9. Jovanovic S, Spiekermann H, Richter E. Bone regeneration around titanium dental implants in dehisced defect sites. A clinical study. Int J Oral Maxillofac Implants 1992; 7:233-245

10. Hall E, Meffert R, Herman J, Mellonig J, Cochran D. Comparison of bioactive glass to demineralized freeze-dried bone allograft in the treatment of intrabony defects around implants in the canine mandible. J Periodontol 1999;70:526-535.

11. Becker W, Dahlin C, Becker BE, Lekholm U, van Steenberghe D. The use of e-PTFE barrier membranes for bone promotion around titanium implants placed into extraction sockets: A prospective multicenter study. Int J Oral Maxillofac Implants 1994;9:31-40

12. Becker W, Becker B, Polizzi G, Bergstrom C. Autogenous bone grafting of bone defects adjacent to implants placed into immediate extraction sockets in patients: A prospective study. Int J Oral Maxillofac Implants 1994; 9:389-396.

13. Becker W, Schenk M. Variations in bone regeneration adjacent to implants augmented with barrier membranes alone or with demineralized freeze-dried bone or autologous grafts: A study in dogs. Int J Oral Maxillofac Implants 1995; 10: 143-154.

14. Shallhorn R, Present status of osseous grafting procedures. Journal of Periodontology 1977; 48(9): 570-76.

15. Sheikh Z, Sima C, Glogauer M. Bone replacement materials and techniques used for achieving vertical alveolar bone augmentation. Materials 2015; 8: $2953-2993$.

16. Esposito M, Grusovin M, Felice P, Karatzopoulos G, Worthington H, Coulthard P. The efficacy of horizontal and vertical bone augmentation procedures for dental implants - a Cochrane systematic review. European journal of oral implantology 2009;2(3): 167-184.

17. Fiorellini JP, Engebretson SP, Donath K, Weber HP. Guided bone regeneration utilizing expanded polytetrauoroeth-ylene membranes in combination with submerged and nonsubmerged dental implants in beagle dogs. J Periodontol 1998;69:528-535.

18. Retzepi M, Donos N. Guided bone regeneration: biological principle and therapeutical applications. Clin Oral Implants Res 2010; $21: 567$ - 576.

19. Chiapasco M, Zaniboni M. Clinical outcomes of GBR procedures to correct peri-implant dehiscences and fenestration: a systematic review; Clin Oral Implants Res 2009; 20: 113-123.

20. McAllister B, Haghighat K. Bone augmentation techniques. J Periodontol 2007; 78: 377-396.

21. Von Arx T, Hardt N, Wallkamm B. The time technique: a new method for localized alveolar ridge augmentation prior to placement of dental implants. Int J Oral Maxillofac Implant 1996; 11: 387-394.

22. Von Arx T, Buser D. Horizontal ridge augmentation using autogenous block grafts and the guided bone regeneration technique with collagen membranes: a clinical study with 42 patients. Clin Oral Implant Res 2006; 17: 359-366.

23. Her S, Kang T, Fien MJ. Titanium mesh as an alternative to a membrane for ridge augmentation. J Oral Maxillofac Surg 2012; 70(4): 803-10.

24. Gluckman H, Du Toit J. Guided bone re-generation using a titanium membrane at implant placement: A case report and literature discussion. International Dentistry African Edition 2014; 4: 20-29.

25. Celletti R, Davarpanah M, Etienne D, Pecora G, Tecucianu JF, Djukanovic D, et al. Guided tissue regeneration around dental implants in immediate extraction sockets: comparison of e-PTFE and a new titanium membrane. Int J Periodontics Restorative Dent 1994 Jun; 14(3): 242-53.

26. Rakhmatia YD, Ayukawa Y, Furuhashi A, Koyano K. Current barrier membranes: titanium mesh and other membranes for guided bone regeneration in dental applications, J Prosthodont Res 2013; 57(1): 3-14.

27. Sakr A, Shaaban A, Elsheikh. Evaluation of the effects of I-Gen Titanium membrane around immediate dental implants replacing posterior mandibular tooth with buccal bone defect, Alexandria Dental Journal 2017; 42: 85-91. 